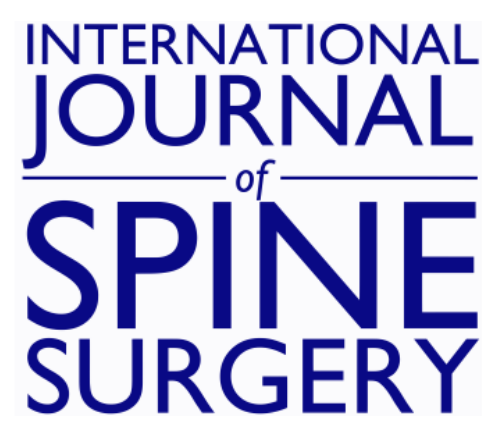

\title{
Stability and Load Sharing Characteristics of a Posterior Dynamic Stabilization Device
}

Daniel J. Cook, Matthew S. Yeager, Shankar S. Thampi, Donald M. Whiting and Boyle C. Cheng

Int J Spine Surg 2015, 9 ()

doi: https://doi.org/10.14444/2009

http://ijssurgery.com/content/9/9

This information is current as of April 26, 2023.

Email Alerts Receive free email-alerts when new articles cite this article. Sign up at:

http://ijssurgery.com/alerts

The International Journal of Spine Surgery

2397 Waterbury Circle, Suite 1,

Aurora, IL 60504, Phone: +1-630-375-1432 


\section{Stability and Load Sharing Characteristics of a Posterior Dynamic Stabilization Device}

Daniel J. Cook, MS,1 Matthew S. Yeager, BS, ${ }^{1}$ Shankar S. Thampi, BS, 2 Donald M. Whiting, MD,1,2 Boyle C. Cheng, PhD1,2

${ }_{1}^{1}$ Allegheny Health Network, Department of Neurosurgery, Pittsburgh, $P A{ }^{2}$ Drexel University College of Medicine, Pittsburgh, PA

\section{Abstract}

\section{Background}

Lumbar interbody fusion is a common treatment for a variety of spinal pathologies. It has been hypothesized that insufficient mechanical loading of the interbody graft can prevent proper fusion of the joint. The purpose of this study was to evaluate the mechanical stability and anterior column loading sharing characteristics of a posterior dynamic system compared to titanium rods in an anterior lumbar interbody fusion (ALIF) model.

\section{Methods}

Range of motion, interpedicular kinematics and interbody graft loading were measured in human cadaveric lumbar segments tested under a pure moment flexibility testing protocol.

\section{Results}

Both systems provided significant fixation compared to the intact condition and to an interbody spacer alone in flexion extension and lateral bending. No significant differences in fixation were detected between the devices. A significant decrease in graft loading was detected in flexion for the titanium rod treatment compared to spacer alone. No significant differences in graft loading were detected between the spacer alone and posterior dynamic system or between the posterior dynamic system and the titanium rod.

\section{Conclusions}

The results of this study indicate that the posterior dynamic system provides similar fixation compared to that of a titanium rod, however, studies designed to evaluate the efficacy of fixation in a cadaver model may not be sufficiently powered to establish differences in load sharing using the techniques described here.

KEYWORDS: LUMBAR SPINE BIOMECHANICS, POSTERIOR DYNAMIC STABILIZATION, LOAD SHARING

VOLUME 9 ARTICLE 9 DOI: 10.14444/2009

\section{Introduction}

The standard treatment for a variety of advanced degenerative spinal pathologies is arthrodesis of the affected motion segments. This often follows a procedure of direct or indirect decompression of the afflicted neural tissue. Arthrodesis, or joint fusion, is often warranted following decompression because of mechanical instability of the joint, either as a result of degenerative changes leading up to surgical intervention or due to tissue disruption caused by the decompression procedure itself. Fusion of the index level is aided by a graft material consisting of either a synthetic bone substitute or bony tissue derived from the patient (autograft) or a donor (allograft). Internal fixation devices, consisting of such implants as screws, rods, plates and interbody spacers, have emerged as useful adjuncts to the fusion graft by providing immobilization of the joint during the fusion process.

The rate of pseudarthrosis, or the failure of successful fusion, has been reported at a variety of ranges depending on factors such as the specific pathology treated, the surgical technique, the technique used to assess the non-union, the number of levels fused and the presence of any metabolic abnormalities. ${ }^{1-3}$ In an effort to reduce the rate of non-union, creating the optimal environment for bone growth, thereby expediting fusion and fostering positive clinical outcomes, has become a focus of research regarding spine surgery. The influence of exogenous substances, 
such as non-steroidal anti-inflammatory drugs and nicotine, on the rate of bone growth has been well characterized, ${ }^{3,4}$ and according recommendations for care have been made standard. Recombinant human bone morphogenic proteins have been developed to accelerate bone apposition and, despite controversies surrounding complications and appropriate indications, ${ }^{5-7}$ have demonstrated success in patients with comorbidities known to inhibit proper bone healing. ${ }^{8}$

Beyond mechanical joint stability and an optimal biochemical environment, it is well known that the state of mechanical stress is influential in bone metabolism. ${ }^{9}$ It has been hypothesized that overly stiff adjuncts to fusion could result in states of stress within the fusion graft too low to properly facilitate arthrodesis. The elimination of this so-called stress shielding has become the design rationale for a class of internal fixators known as dynamic stabilization devices. ${ }^{10-12}$ Most devices falling within this classification have been designed as modifications to the ubiquitous pedicle screw and titanium rod constructs. The simplest modification is perhaps the introduction of polyetheretherketone (PEEK) rods of the same dimensions as the preceding titanium rods with the expectation that the more compliant material would prevent stress shielding of the graft. More complex systems have been developed consisting of compliant components, such as DYNESYS (Zimmer Spine, Minneapolis, MN) and TRANSITION (Globus Medical, Audubon, PA), and mechanical joints, such as ISOBAR (Scient'x, Guyancourt, France) and DSS (Paradigm Spine, New York, NY).

Multiple studies have been conducted using human cadaveric specimens to investigate the load sharing properties of different types of fusion implants. Freeman et al. and Rapoff et al. estimated the load sharing characteristics of various anterior cervical plates without direct measurement of implant loading. ${ }^{13,14}$ Cheng et al. and Brodke et al. evaluated the load sharing characteristics of anterior cervical plates using modified interbody spacers with integrated subminiature load cells. ${ }^{15,16}$ Reidy et al. measured the load within a modified corpectomy spacer using a subminiature load cell and also measured the strain within the accompanying static and dynamic cervical plates using strain gauges. ${ }^{17}$ In the lumbar spine, $\mathrm{Yu}$ et al. measured anterior column load sharing with the ISOBAR posterior dynamic rod utilizing a modified transforaminal interbody spacer with an integrated subminiature load cell. ${ }^{10}$ These studies were limited to measurement of axial compressive load due to their reliance on uniaxial, compression-only load cells. Cripton et al. thoroughly characterized the sixaxis load sharing properties of pedicle screw and rod constructs by placing strain gauges on the rods and measuring intradiscal pressure.$^{18}$ However, a fusion graft was not incorporated into the study, limiting interpretation related to interbody fusion constructs.

The load distribution within six different thoracolumbar anterior instrumentation systems was investigated by Brodke et al. using pressure sensitive film inserted between simulated vertebral bodies and corpectomy spacers, both constructed of ultra-high molecular weight polyethylene (UHMWPE). ${ }^{19}$ While an inverse relationship was found between load sharing and implant stiffness, the experimental model did not accurately simulate human anatomy, but rather, relied upon a simple cylindrical geometry and the consistent material properties of a synthetic material. Similarly, Sengupta et al. showed greater load sharing in the TRANSITION system compared to polyetheretherketone (PEEK) and titanium rods in a loading condition similar to the ASTM F1717 corpectomy model utilizing UHMWPE blocks. ${ }^{20}$

In summary, there exists a considerable body of data on the distribution and magnitude of loads across a simulated interbody device placed between flat, UHMWPE blocks in conjunction with adjuncts (rods and plates) of varying stiffness. However, given the differences between human vertebrae and UHMW$\mathrm{PE}$ blocks with regard to shape and material properties, this data is of limited clinical significance. On the other hand, data on load sharing within the interbody graft in cadaveric models has been limited to uniaxial compression measurements. The purpose of this study was to evaluate the mechanical stability and anterior column load sharing characteristics of the TRANSITION posterior dynamic system (PDS) compared to titanium rods in an anterior lumbar interbody fusion (ALIF) model. A specially designed interbody spacer was used in conjunction with pressure sensitive film in order to measure the load distri- 
bution across the graft in axial compression as well as bending modes of loading. The relative kinematics between adjacent pedicle screws was also directly monitored using an optoelectric tracking system.

\section{Materials and Methods}

Six fresh frozen human lumbar cadaveric specimens were stripped of all soft tissue except for the osteoligamentous structures. Each specimen was dualenergy X-ray absorptiometry scanned for bone mineral density. Four active light emitting diodes (LED) were permanently affixed to the anterior surface of each vertebra for optoelectric tracking. Table 1 lists the demographic information for each specimen. The ends of each specimen (T12 and sacrum) were dissected to fit within aluminum potting rings and then affixed to the rings with a combination of screws and potting resin (Bondo, 3M, Atlanta, GA). All specimens were stored in double sealed bags and maintained at $-20^{\circ} \mathrm{C}$ when not in use.

Flexibility testing was conducted on each specimen in a six-degree-of-freedom spine testing apparatus (Bose, Smart Test Series, Eden Prairie, MN) under a pure moment flexibility protocol including flexion extension (FE), lateral bending (LB), axial torsion (AT) and axial compression (AC) modes of loading. All rotational modes (FE, LB, AT) consisted of sinusoidal loading to limits of $\pm 7.5 \mathrm{Nm}$ at a frequency of 0.005 $\mathrm{Hz}$. Axial compression testing consisted of loading to $150 \mathrm{~N}$ at the same frequency. The three-dimensional kinematic response of each vertebra to loading was monitored using an Optotrak Certus motion capture system (Northern Digital Inc., Waterloo, ON, Canada).

\begin{tabular}{|c|c|c|c|c|c|}
\hline Specimen \# & Age (yr) & Sex & Height (in) & Weight (lb) & BMD $\left(\mathrm{g} / \mathrm{cm}^{2}\right)$ \\
\hline MD11122149 & 61 & $\mathrm{~F}$ & 63 & 230 & 0.782 \\
\hline MI11120709 & 64 & $\mathrm{~F}$ & 59 & 155 & 0.717 \\
\hline LA11110202 & 44 & M & 72 & 280 & 0.855 \\
\hline IN12010102 & 66 & $\mathrm{~F}$ & 61 & 222 & 0.779 \\
\hline MD12021541 & 47 & M & 68 & 140 & 0.845 \\
\hline MD11102771 & 64 & M & 74 & 240 & 0.878 \\
\hline
\end{tabular}

A series of specially designed PEEK ALIF spacers was manufactured in order to allow for the measurement of anterior column loading during biomechanical testing. The typical ALIF spacer design was modified so that a single graft window was cut out of the top portion of the spacer. A PEEK plunger was machined for each implant height to fit within the graft window and to extend $2 \mathrm{~mm}$ above the top of the body of the spacer. A slot was machined into the anterior surface of the spacer so that pressure sensitive film (I-scan, Tekscan, Boston, MA) could be inserted in order to measure the load transferred through the graft window plunger. This was done to ameliorate measurement error resulting from the use of pressure sensitive film on the uneven surfaces of typical ALIF spacers and the vertebral endplate. Casts of the upper and lower surfaces of the spacer were made from potting resin (Bondo) in order to ensure upright orientation of the spacer during calibration. Before insertion of the spacer into the interbody space for testing, a $10 \mathrm{~kg}$ weight was placed upon the cagefilm-cast construct for calibration using the Tekscan software (Iscan, ver. 6.02). A spacer with film inserted and implanted at L4-5 is shown in Figure 1A. The spacer, partially removed from the interbody space following testing, is shown in Figure 1B.

Custom clamps were also designed in order to track the head of each left-side pedicle screw during testing for each of the treatment conditions. This is shown in Figure 2 and was done to calculate the interpedicular kinematics of each treatment. Two set screws on either side of each clamp were digitized using a probe and virtually tracked relative to their respective LED for the calculation of interpedicular kinematics. Pedicle screws were implanted prior to testing of the Intact condition so that interpedicular kinematics could be measured in the same manner for all treatment conditions.

Surgical treatment conditions were carried out in the following order with flexibility testing, as described above, conducted following each treatment:

1. Intact segment with pedicle screws at L4-5 (Intact

2. ALIF with PDS at L4-5 (PDS) 
3. ALIF with titanium rod at L4-5 (Titanium)

4. ALIF without supplemental fixation (Spacer On-

ly)

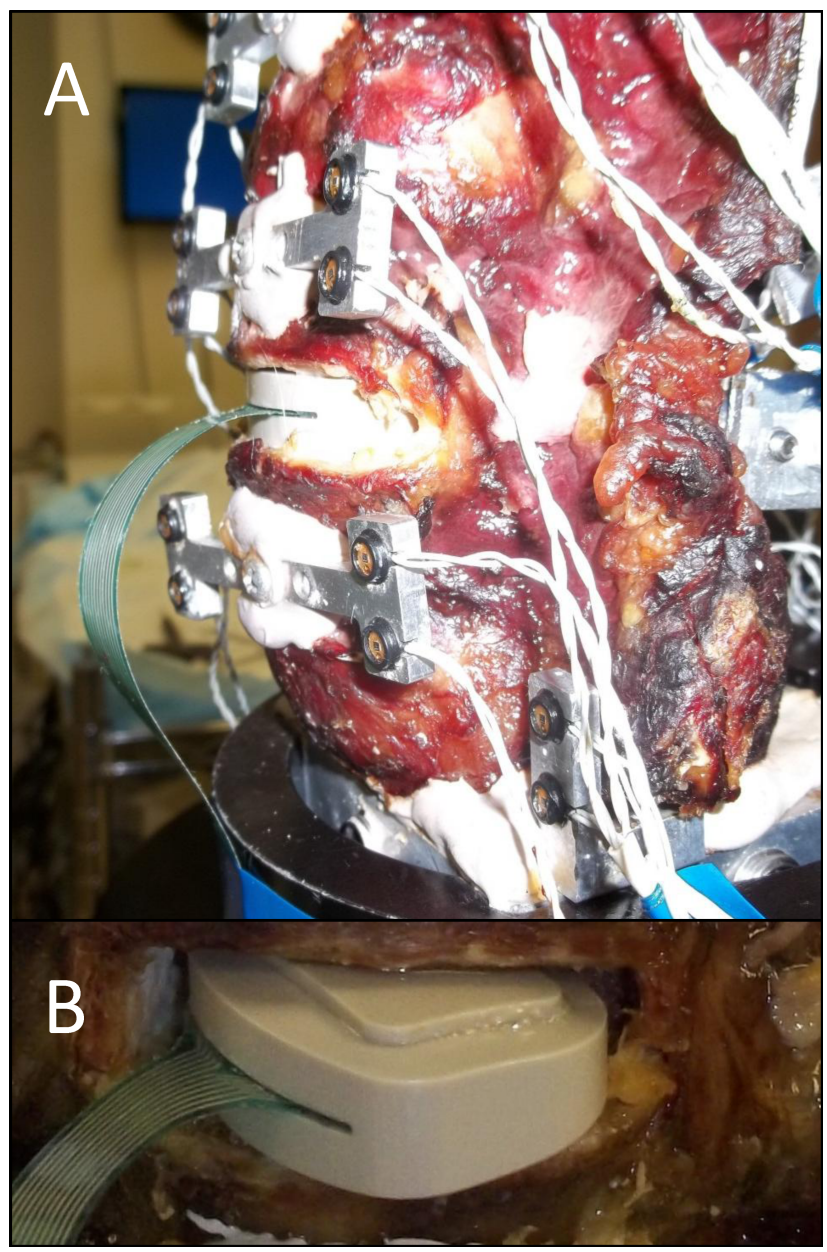

Fig. 1. A - ALIF Spacer with Tekscan Inserted into Lumbar Segment. B ALIF Spacer with Tekscan Partially Removed from Interbody Space to Illustrate Design.

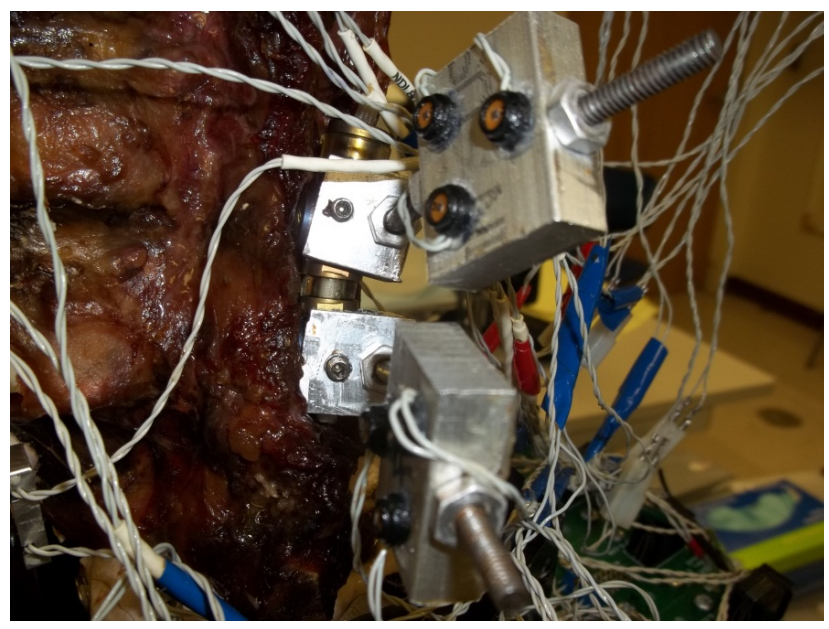

Fig. 2. Tracking Fixtures Affixed to Pedicle Screws During Testing of PDS.
The PDS device tested, shown in Figure 3 to the left of a $5.5 \mathrm{~mm}$ titanium rod used in the study, consists of two polycarbonate urethane spacers surrounding a polyethylene terephthalate cord on titanium spools which are placed between adjacent pedicle screws. The device is designed to allow for small changes in interpedicular travel (IPT) during flexion and extension motion. ${ }^{20}$

Range of motion (ROM) was calculated as the range (maximum-minimum) of the Euler angle corresponding to each bending and torsion mode of loading (FE, $\mathrm{LB}, \mathrm{AT}$ ) and as axial displacement for AC during the third cycle of flexibility testing. IPT and interpedicular displacement (ID), which quantify the magnitude of motion between adjacent pedicle screws throughout the range of movement, were calculated by a method previously described. ${ }^{21}$ The total compressive force exerted on the film (Axial Graft Loading), and the Center of Force (COF), were exported from the Tekscan data recording software for each test conducted. These two values were used to calculate bending moments (FE and LB) transmitted through the graft at all testing time points. These moments

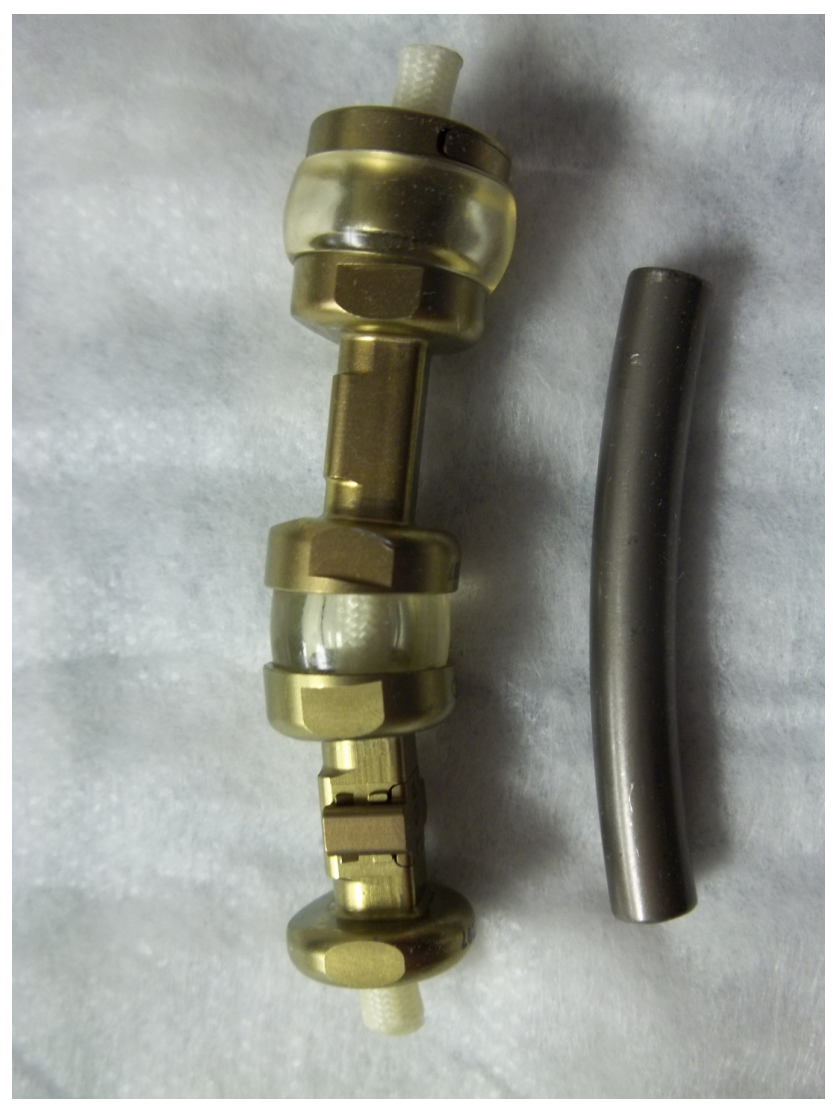

Fig. 3. PDS Device (left) and $5.5 \mathrm{~mm}$ Titanium Rod (right). 
were calculated as the product of the total force magnitude $(\mathrm{F})$ and the respective coordinates of the $\mathrm{COF}$ $\left(D_{x}\right.$ and $\left.D_{y}\right)$ with respect to the center of the film sensor as described in the following equations and in Figure 4.

\section{Statistical Methods}

A one-way, mixed-effects analysis of variance (ANOVA) with Bonferroni-corrected post hoc pairwise comparison was conducted for each of the outcome measures described. All statistical analysis was conducted in SPSS (IBM, Armonk, New York).

\section{Results}

\section{ROM}

A significant reduction in FE ROM was detected for all treated conditions with respect to Intact $(\mathrm{p} \leq 0.032)$ and for PDS and Titanium with respect to Spacer Only $(\mathrm{p}<0.001)$. A significant reduction in LB ROM was detected for both PDS and Titanium with respect to Intact $(\mathrm{p} \leq 0.001)$ and for PDS and Titanium with respect to Spacer Only $(\mathrm{p}<0.001)$. A statistically significant increase in AT ROM was detected for the Spacer Only treatment with respect to Titanium $(\mathrm{p}=0.001)$. A statistically significant decrease in AC ROM was detected for each instrumented treatment condition with respect to Intact $(\mathrm{p}<0.040)$. No significant differences in FE, LB, AT or AC ROM were detected between the PDS and Titanium treatments. These results are displayed in Figure 5 and shown in Table 2.

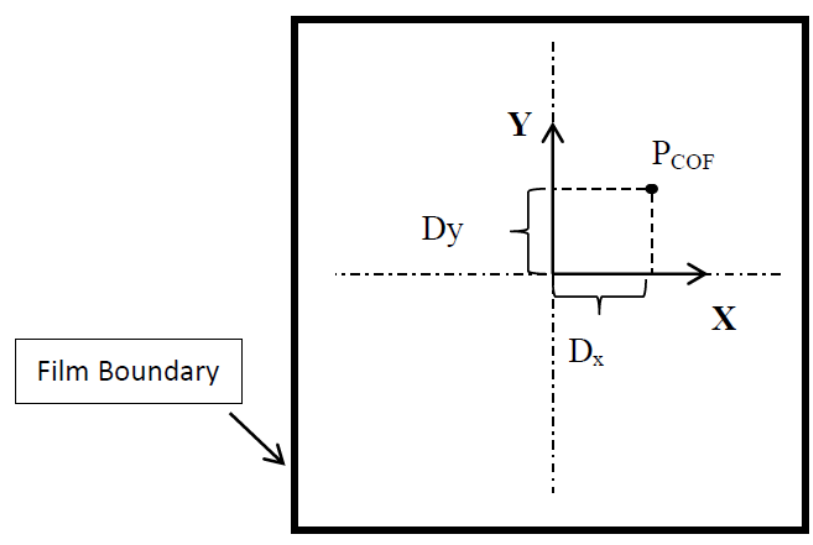

Fig. 4. Bending Moment Calculations.
IPT

A significant reduction in IPT was detected during FE for PDS and Titanium with respect to the Intact condition ( $\mathrm{p}=0.005$ and 0.027 respectively). A significant reduction in IPT was detected during LB for PDS and Titanium with respect to the Intact condition ( $\mathrm{p}=0.036$ and 0.015 respectively). A significant increase in IPT was detected for the Spacer Only treatment with respect to Titanium during $\mathrm{LB}$ $(p=0.005)$. A significant increase in IPT was detected during AT for the Spacer Only treatment with respect to both Intact and Titanium ( $\mathrm{p}=0.049$ and 0.026 respectively). A significant reduction in IPT

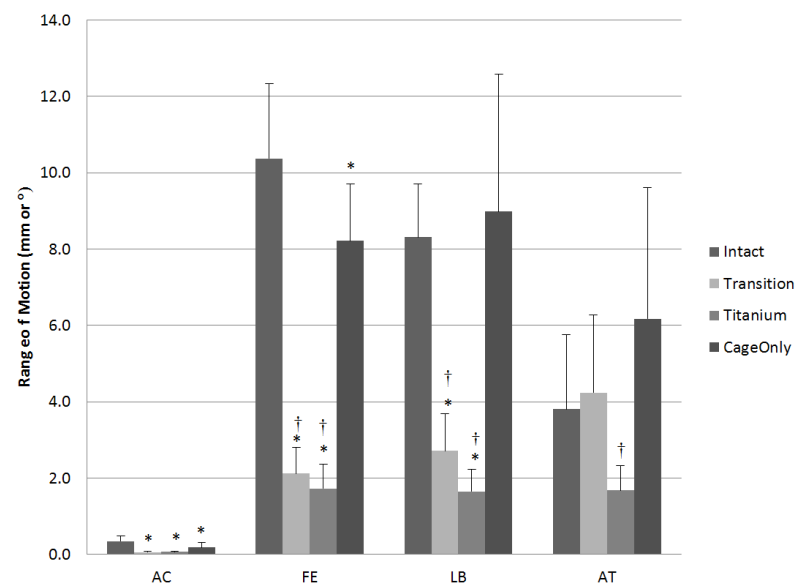

Fig. 5. ROM Summary (* = Significantly Different Compared to Intact; † = Significantly Different Compared to Spacer Only).

\begin{tabular}{|c|c|c|c|c|c|}
\hline & & Intact & TRANSITION & Titanium & $\begin{array}{r}\text { Spacer } \\
\text { Only }\end{array}$ \\
\hline \multirow{2}{*}{$\begin{array}{l}\text { Axial Compres- } \\
\text { sion }(\mathrm{mm})\end{array}$} & mean & 0.35 & 0.06 & 0.07 & 0.18 \\
\hline & std & 0.13 & 0.03 & 0.02 & 0.13 \\
\hline \multirow{2}{*}{$\begin{array}{l}\text { Flexion Exten- } \\
\text { sion }\left({ }^{\circ}\right)\end{array}$} & mean & 10.38 & 2.12 & 1.73 & 8.22 \\
\hline & std & 1.95 & 0.69 & 0.63 & 1.49 \\
\hline \multirow{2}{*}{$\begin{array}{l}\text { Lateral Bending } \\
\left({ }^{\circ}\right)\end{array}$} & mean & 8.31 & 2.71 & 1.65 & 8.17 \\
\hline & std & 1.39 & 0.97 & 0.58 & 3.36 \\
\hline \multirow{2}{*}{ Axial Torsion $\left({ }^{\circ}\right)$} & mean & 3.81 & 4.24 & 1.68 & 7.00 \\
\hline & std & 1.94 & 2.04 & 0.65 & 3.11 \\
\hline
\end{tabular}


was detected during AC for PDS with respect to the Intact condition ( $p=0.028)$. No significant differences in FE, LB, AT or AC IPT were detected between the PDS and Titanium treatments. IPT results are summarized in Table 3.

\section{ID}

A significant reduction in FE ID was detected for all treated conditions with respect to Intact $(\mathrm{p} \leq 0.012)$ and for PDS and Titanium with respect to Spacer Only $(\mathrm{p}<0.001)$. A significant reduction in LB ID was detected for PDS and Titanium with respect to Intact $(\mathrm{p} \leq 0.001)$ and Spacer Only $(\mathrm{p} \leq 0.001)$. A significant increase in AT ID was detected for the Spacer Only treatment with respect to all others $(\mathrm{p} \leq 0.012)$. A significant reduction in AC ID was detected for PDS and Titanium with respect to Intact $(\mathrm{p} \leq 0.006)$ and Spacer Only $(\mathrm{p} \leq 0.012)$. No significant differences in FE, LB, AT or AC ID were detected between the PDS and Titanium treatments. ID results are summarized in Table 4.

\section{Graft Loading}

The load distribution during peak flexion and peak extension across the pressure sensitive film for a representative sample of the test specimens is shown for each treatment in Figure 6. Regions of higher pressure are denoted in red, while blue represents regions

\begin{tabular}{|c|c|c|c|c|c|}
\hline & & Intact & TRANSITION & Titanium & $\begin{array}{r}\text { Spacer } \\
\text { Only }\end{array}$ \\
\hline \multirow{2}{*}{$\begin{array}{l}\text { Axial Compres- } \\
\text { sion (mm) }\end{array}$} & mean & 1.16 & 0.68 & 0.67 & 1.07 \\
\hline & std & 0.27 & 0.52 & 0.39 & 0.49 \\
\hline \multirow{2}{*}{$\begin{array}{l}\text { Flexion Exten- } \\
\text { sion }(\mathbf{m m})\end{array}$} & mean & 8.04 & 5.32 & 5.23 & 6.70 \\
\hline & std & 2.05 & 2.43 & 2.73 & 2.00 \\
\hline \multirow{2}{*}{$\begin{array}{l}\text { Lateral Bending } \\
(\mathrm{mm})\end{array}$} & mean & 8.81 & 7.40 & 6.61 & 7.90 \\
\hline & std & 2.85 & 2.45 & 2.33 & 2.36 \\
\hline \multirow{2}{*}{$\begin{array}{l}\text { Axial Torsion } \\
(\mathrm{mm})\end{array}$} & mean & 3.90 & 6.05 & 4.49 & 6.93 \\
\hline & std & 1.74 & 2.40 & 0.90 & 3.07 \\
\hline
\end{tabular}

of lower pressure. As expected there was considerably greater graft loading during flexion than during extension, though no statistical comparisons were made between loading conditions. Further, there was an anticipated trend for greater total axial graft loading for the Spacer Only condition compared to both Titanium and PDS and for greater loading in PDS compared to Titanium. However, only the comparison between Spacer Only and Titanium was statistically significant during Flexion $(\mathrm{p}=0.002)$ and Left Bending ( $\mathrm{p}=0.046)$. An unexpected significant increase in axial graft loading was detected for the Titanium treatment compared to Spacer Only in Right Bending ( $p=0.009)$. These significant differences are denoted in Figure 7 along with the mean and standard deviation across specimens for Axial Graft Loading in all peak loading conditions.

No significant differences were found in FE moment graft loading between any treatment conditions at any peak loading condition as shown in Figure 8. A significant increase in LB moment graft loading was detected at peak Left Bending for the Spacer Only treatment with respect to Titanium $(\mathrm{p}=0.009)$. A significant increase in LB moment graft loading was detected at peak Right AT for the Spacer Only treatment with respect to Titanium $(\mathrm{p}=0.042)$. These differences are illustrated in Figure 9.

\begin{tabular}{|c|c|c|c|c|c|}
\hline & & Intact & TRANSITION® & Titanium & $\begin{array}{r}\text { Spacer } \\
\text { Only }\end{array}$ \\
\hline \multirow{2}{*}{$\begin{array}{l}\text { Axial Compres- } \\
\text { sion }(\mathrm{mm})\end{array}$} & mean & 0.96 & 0.03 & 0.03 & 0.85 \\
\hline & std & 0.29 & 0.02 & 0.02 & 0.54 \\
\hline \multirow{2}{*}{$\begin{array}{l}\text { Flexion Exten- } \\
\text { sion }(\mathrm{mm})\end{array}$} & mean & 7.54 & 0.14 & 0.04 & 5.61 \\
\hline & std & 1.54 & 0.04 & 0.03 & 1.06 \\
\hline \multirow{2}{*}{$\begin{array}{l}\text { Lateral Bending } \\
(\mathrm{mm})\end{array}$} & mean & 4.72 & 0.23 & 0.08 & 4.62 \\
\hline & std & 1.28 & 0.13 & 0.05 & 1.53 \\
\hline \multirow{2}{*}{$\begin{array}{l}\text { Axial Torsion } \\
(\mathrm{mm})\end{array}$} & mean & 0.73 & 0.15 & 0.14 & 2.25 \\
\hline & std & 0.64 & 0.07 & 0.09 & 1.32 \\
\hline
\end{tabular}




\section{Discussion}

Both forms of interpedicular stabilization investigated in this study contributed to a significant reduction in FE and LB ROM when used in conjunction with an ALIF spacer, compared to the Intact condition and the Spacer Only treatment condition. Only the titanium rod provided any statistically significant stabilization in AT ROM. Similar findings were made in IPT and ID when directly measured from the pedicle screw heads. Given the differential in rod designs, es-
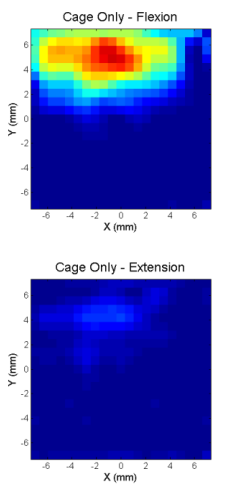

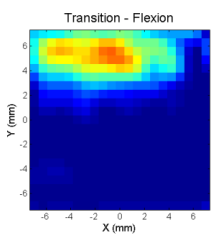

$\mathrm{x}(\mathrm{mm})$

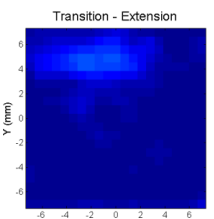

$\mathrm{x}(\mathrm{mm})$

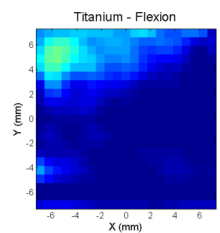

$\mathrm{x}(\mathrm{mm})$

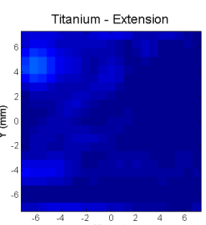

${ }^{2} \times(\mathrm{mm})$
Fig. 6. Representative Sample Pressure Distribution at Peak Flexion and Peak Extension (Red regions correspond to greater pressure on the film. The $y$-axis is oriented anteriorly and the $x$-axis is oriented to the right.)

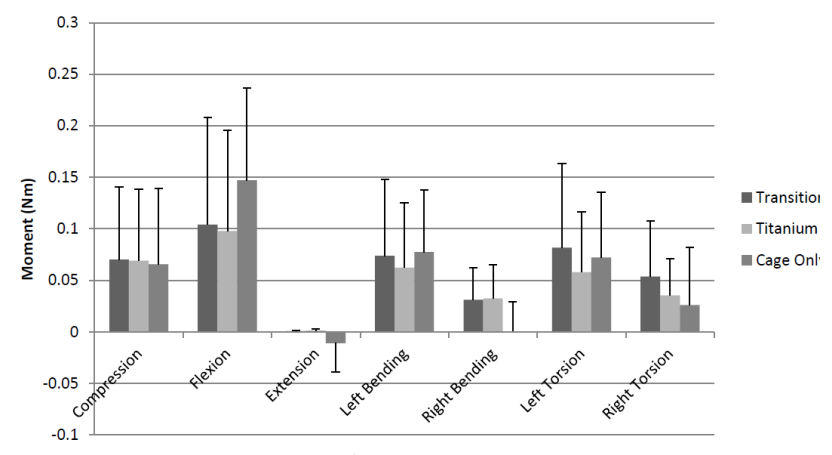

Fig. 7. Axial Compressive Load $(\dagger=$ Significantly Different Compared to Spacer Only).

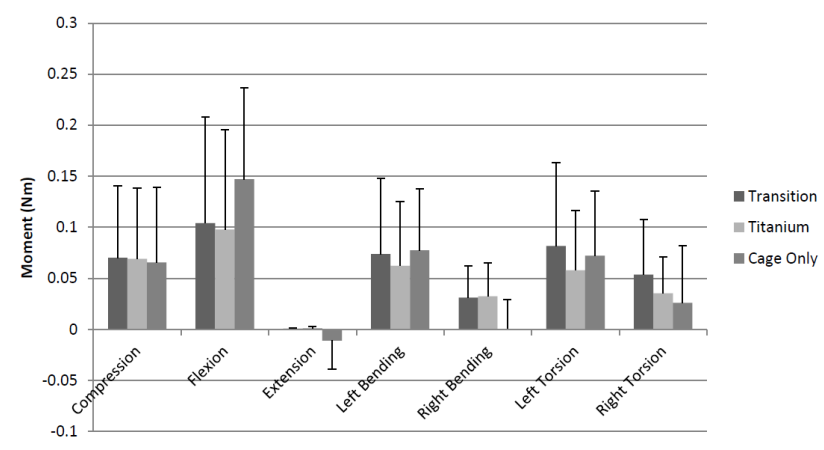

Fig. 8. Flexion Extension Moment Graft Loading. pecially with regard to axial stiffness, the lack of any significant differences between the two in ID during $\mathrm{FE}$ and LB is somewhat surprising. However, the mean FE ID for PDS and Titanium (0.14 and 0.04 $\mathrm{mm}$ respectively) are comparable to the reported accuracy of the Optotrak system used in this study and are drastically smaller than Intact ID $(7.54 \mathrm{~mm})$. This finding suggests that in order to measure a differential effect between these two treatment conditions, that a more accurate measurement system or a greater sample size may be required. Overall, no significant differences in kinematics were found between the PDS and Titanium rod treatment conditions, indicating that both devices are similarly suited, biomechanically, for the primary design intent of fixating adjacent lumbar vertebrae.

On the contrary, in a study of a device with similar design characteristics to the PDS device used in the current study, Lazaro et al. found significantly greater LB and AT ROM in the flexible rod compared to a titanium rod. ${ }^{22}$ However, it is critical to note that this study investigated both implants as stand-alone devices with no interbody spacer, constituting a motion-preserving construct which is a commonly referenced configuration for this class of devices. ${ }^{23-25}$ Since the current study was designed to elucidate differences in fixation and load sharing of the two devices used in an adjunct-to-fusion model, no evaluation of the devices as stand-alone fixation was conducted. Thus no conclusions regarding their relative performance in the absence of an interbody spacer can be drawn. The stabilizing effect of the interbody spacer may explain, in part, the absence of any significant kinematic differences between the constructs.

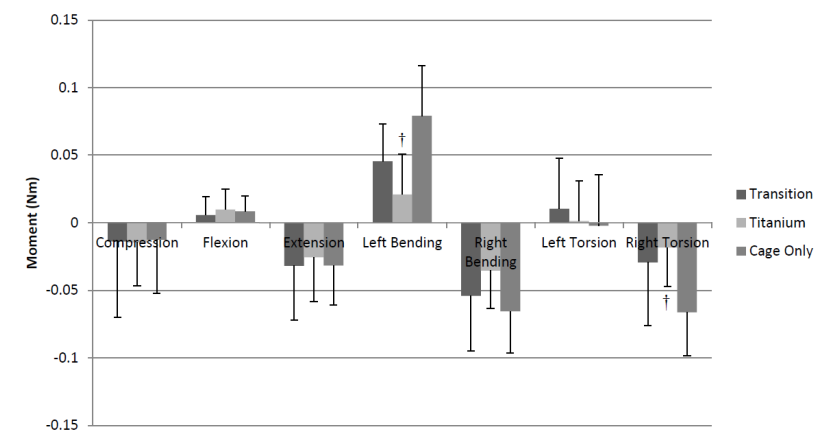

Fig. 9. Lateral Bending Moment Graft Loading ( $†=$ Significantly Different Compared to Spacer Only). 
While several in vitro biomechanical studies have been published investigating the stability of posterior dynamic devices ${ }^{26-30}$, few have investigated their load sharing characteristics in an interbody fusion model. Studies have investigated the influence of posterior dynamic implants on intradiscal pressure at the index level, however these results are difficult to compare to the current study since the technique of measurement is different and the devices were tested in a non-fusion model. ${ }^{31-33}$ Also, the load sharing characteristics of the devices tested in this study and ones like them have been evaluated in simplified synthetic models. ${ }^{20}$ The authors have sought in this study to evaluate the load distribution through an interbody spacer using integrated, pressure-sensitive film in a lumbar human cadaveric model. Significant decreases in graft loading were found for the Titanium rod compared to the Spacer Only treatment condition in flexion, but no significant differences were found between PDS and Spacer Only or between the two rods.

This study suffers from limitations inherent in all cadaveric biomechanical tests. The scarcity and expense of cadaveric tissue imposes sample size limitations that hamper statistical power for any but very large effects. Further, the pure moment flexibility protocol represents a simplified loading regimen that may not strictly simulate the physiologic loading environment. There were also limitations with respect to the design of the modified ALIF spacer. In an attempt to mitigate error associated with pressure sensitive film measurement between dissimilar surfaces, the spacer was modified so that pressure measurements could be made between machined surfaces of the same material. However, pressure measurement across the entire cross-section of the spacer was not possible because there would have been nothing to limit shearing dissociation between the two halves of the implant. This required a trade-off in that only the pressure across the modified graft window was measured. Future work should focus on improving the design of the spacer used to measure anterior column loading. Surface serrations similar to those used clinically should be included to prevent device migration. Alternative techniques for load measurement, such as strain gauges, should be considered in order to overcome the limitations associated with pressure sensitive film.

\section{Conclusions}

The load sharing and kinematic effects of a posterior dynamic stabilization system were compared to that of a titanium rod. Both systems provided statistically significant fixation in FE and LB compared to the Intact condition. No significant differences were found between the two fixation systems used in conjunction with an ALIF spacer. A significant decrease in the total load transferred through the graft was measured for the Titanium rod construct compared to Spacer Only in peak flexion and left LB. Similarly, a significant decrease in bending moment transferred through the graft was measured in peak left LB and peak right AT for the Titanium rod compared to Spacer Only. No such differences were detected for the PDS system.

\section{References}

1. Steinmann JC, Herkowitz HN. Pseudarthrosis of the spine. Clin Orthop Relat Res. Nov 1992(284):80-90.

2. Brantigan JW. Pseudarthrosis rate after allograft posterior lumbar interbody fusion with pedicle screw and plate fixation. Spine (Phila Pa 1976). Jun 1

1994;19(11):1271-1279; discussion 1280.

3. Thaller J, Walker M, Kline AJ, Anderson DG. The effect of nonsteroidal anti-inflammatory agents on spinal fusion. Orthopedics. Mar

2005;28(3):299-303; quiz 304-295.

4. Silcox DH, 3rd, Daftari T, Boden SD, Schimandle JH, Hutton WC, Whitesides TE, Jr. The effect of nicotine on spinal fusion. Spine (Phila Pa 1976). Jul 15 1995;20(14):1549-1553.

5. Vaccaro AR, Patel T, Fischgrund J, et al. A pilot study evaluating the safety and efficacy of OP-1 Putty (rhBMP-7) as a replacement for iliac crest autograft in posterolateral lumbar arthrodesis for degenerative spondylolisthesis. Spine (Phila Pa 1976). Sep 1 2004;29(17):1885-1892.

6. Carragee EJ, Baker RM, Benzel EC, et al. A biologic without guidelines: the YODA project and the future of bone morphogenetic protein-2 research.

Spine J. Oct;12(10):877-880. 
7. Woo EJ. Recombinant human bone morphogenetic protein-2: adverse events reported to the Manufacturer and User Facility Device Experience database. Spine J. Oct;12(10):894-899.

8. O'Shaughnessy BA, Kuklo TR, Ondra SL. Surgical treatment of vertebral osteomyelitis with recombinant human bone morphogenetic protein-2. Spine (Phila Pa 1976). Mar 1 2008;33(5):E132-139.

9. Mow VC, Huiskers R. Basic Orthopaedic Biomechanics And Mechanobiology: Lippincott Williams \& Wilkins; 2005.

10. Yu AK, Siegfried CM, Chew B, et al. Biomechanics of Posterior Dynamic Fusion Systems in the Lumbar Spine: Implications For Stabilization with Improved Arthrodesis. J Spinal Disord Tech. Oct 10. 11. Wilke HJ, Heuer F, Schmidt H. Prospective design delineation and subsequent in vitro evaluation of a new posterior dynamic stabilization system. Spine (Phila Pa 1976). Feb 1 2009;34(3):255-261.

12. Bono CM, Kadaba M, Vaccaro AR. Posterior pedicle fixation-based dynamic stabilization devices for the treatment of degenerative diseases of the lumbar spine. J Spinal Disord Tech. Jul 2009;22(5):376-383.

13. Freeman AL, Derincek A, Beaubien BP, Buttermann GR, Lew WD, Wood KB. In vitro comparison of bioresorbable and titanium anterior cervical plates in the immediate postoperative condition. J Spinal Disord Tech. Dec 2006;19(8):577-583.

14. Rapoff AJ, Conrad BP, Johnson WM, Cordista A, Rechtine GR. Load sharing in Premier and Zephir anterior cervical plates. Spine (Phila Pa 1976). Dec 15 2003;28(24):2648-2650; discussion 2651.

15. Cheng BC, Burns P, Pirris S, Welch WC. Load sharing and stabilization effects of anterior cervical devices. J Spinal Disord Tech. Dec 2009;22(8):571-577.

16. Brodke DS, Klimo P, Jr., Bachus KN, Braun JT, Dailey AT. Anterior cervical fixation: analysis of load-sharing and stability with use of static and dynamic plates. J Bone Joint Surg Am. Jul 2006;88(7):1566-1573.

17. Reidy D, Finkelstein J, Nagpurkar A, Mousavi P, Whyne C. Cervical spine loading characteristics in a cadaveric $\mathrm{C} 5$ corpectomy model using a static and dynamic plate. J Spinal Disord Tech. Apr 2004;17(2):117-122.
18. Cripton PA, Jain GM, Wittenberg RH, Nolte LP. Load-sharing characteristics of stabilized lumbar spine segments. Spine (Phila Pa 1976). Jan 15 2000;25(2):170-179.

19. Brodke DS, Gollogly S, Bachus KN, Alexander Mohr R, Nguyen BK. Anterior thoracolumbar instrumentation: stiffness and load sharing characteristics of plate and rod systems. Spine (Phila Pa 1976). Aug 15 2003;28(16):1794-1801.

20. Sengupta DK, Bucklen B, McAfee PC, Nichols J, Angara R, Khalil S. The Comprehensive Biomechanics and Load-Sharing of Semirigid PEEK and Semirigid Posterior Dynamic Stabilization Systems. Adv Orthop.2013:745610.

21. Cook DJ, Yeager MS, Cheng BC. Interpedicular Travel in the Evaluation of Spinal Implants: An Application in Posterior Dynamic Stabilization. Spine (Phila Pa 1976). Oct 21 2012;37(11):923-931.

22. Lazaro BC, Reyes PM, Newcomb AG, et al. Biomechanics of dynamic rod segments for achieving transitional stiffness with lumbosacral fusion. Neurosurgery. Sep;73(3):517-527.

23. Serhan H, Mhatre D, Defossez H, Bono CM. Motion-preserving technologies for degenerative lumbar spine: The past, present, and future horizons. SAS Journal. 2011;5(3):75-89.

24. Kaner T, Ozer AF. Dynamic stabilization for challenging lumbar degenerative diseases of the spine: a review of the literature. $A d v \mathrm{Or}$ thop.2013:753470.

25. Gomleksiz C, Sasani M, Oktenoglu T, Ozer AF. A short history of posterior dynamic stabilization. Adv Orthop. 2012:629698.

26. Cheng BC, Gordon J, Cheng J, Welch WC. Immediate biomechanical effects of lumbar posterior dynamic stabilization above a circumferential fusion. Spine (Phila Pa 1976). Nov 1 2007;32(23):2551-2557. 27. Wilson DC, Niosi CA, Zhu QA, Oxland TR, Wilson DR. Accuracy and repeatability of a new method for measuring facet loads in the lumbar spine. J Biomech. 2006;39(2):348-353.

28. Niosi CA, Wilson DC, Zhu Q, Keynan O, Wilson DR, Oxland TR. The effect of dynamic posterior stabilization on facet joint contact forces: an in vitro investigation. Spine (Phila Pa 1976). Jan 1 2008;33(1):19-26.

29. Sengupta D, Bucklen B, Ingalhalikar A, 
Muzumdar A, Khalil S. Does Semi-Rigid Instrumentation Using Both Flexion and Extension Dampening Spacers Truly Provide an Intermediate Level of Stabilization? Advances in Orthopedics.2013:9.

30. Strube P, Tohtz S, Hoff E, Gross C, Perka C, Putzier M. Dynamic stabilization adjacent to singlelevel fusion: Part I. Biomechanical effects on lumbar spinal motion. Eur Spine J. Aug 4.

31. Dath R, Sirkett DM, Gheduzzi S, Miles AW. Intradiscal pressure changes with dynamic pedicle screw systems. J Spinal Disord Tech. Jun 2008;21(4):241-246.

32. Schmoelz W, Huber JF, Nydegger T, Claes L, Wilke HJ. Influence of a dynamic stabilisation system on load bearing of a bridged disc: an in vitro study of intradiscal pressure. Eur Spine J. Aug 2006;15(8):1276-1285.

33. Charles YP, Persohn S, Steib JP, Mazel C, Skalli W. Influence of an Auxiliary Facet System on Lum- bar Spine Biomechanics. Spine (Phila Pa 1976). May

14.

\section{Disclosures}

This work was sponsored by Globus Medical.

\section{Corresponding Author}

Boyle C. Cheng, Ph.D., Department of Neurosurgery, Allegheny General Hospital, 420 East North Avenue, Ste 302, Pittsburgh, PA 15212.

boylecheng@yahoo.com

Published 30 March 2015.

This manuscript is generously published free of charge by ISASS, the International Society for the Advancement of Spine Surgery. Copyright @ 2015 ISASS. To see more or order reprints or permissions, see http://ijssurgery.com. 